\title{
The effect of resource history on the functioning of soil microbial communities is maintained across time
}

\author{
A. D. Keiser ${ }^{1}$, M. S. Strickland ${ }^{1}$, N. Fierer ${ }^{2,3}$, and M. A. Bradford ${ }^{1}$ \\ ${ }^{1}$ School of Forestry and Environmental Studies, Yale University, New Haven, CT, 06511, USA \\ ${ }^{2}$ Department of Ecology and Evolutionary Biology, University of Colorado, Boulder, CO, 80309, USA \\ ${ }^{3}$ Cooperative Institute for Research in Environmental Sciences, University of Colorado, Boulder, CO, 80309, USA
}

Received: 28 January 2011 - Published in Biogeosciences Discuss.: 23 February 2011

Revised: 18 May 2011 - Accepted: 25 May 2011 - Published: 9 June 2011

\begin{abstract}
Historical resource conditions appear to influence microbial community function. With time, historical influences might diminish as populations respond to the contemporary environment. Alternatively, they may persist given factors such as contrasting genetic potentials for adaptation to a new environment. Using experimental microcosms, we test competing hypotheses that function of distinct soil microbial communities in common environments $\left(\mathrm{H} 1_{\mathrm{a}}\right)$ converge or $\left(\mathrm{H} 1_{\mathrm{b}}\right)$ remain dissimilar over time. Using a $6 \times 2$ (soil community inoculum $\times$ litter environment) full-factorial design, we compare decomposition rates in experimental microcosms containing grass or hardwood litter environments. After 100 days, communities that develop are inoculated into fresh litters and decomposition followed for another 100 days. We repeat this for a third, 100-day period. In each successive, 100-day period, we find higher decomposition rates (i.e. functioning) suggesting communities function better when they have an experimental history of the contemporary environment. Despite these functional gains, differences in decomposition rates among initially distinct communities persist, supporting the hypothesis that dissimilarity is maintained across time. In contrast to function, community composition is more similar following a common, experimental history. We also find that "specialization" on one experimental environment incurs a cost, with loss of function in the alternate environment. For example, experimental history of a grass-litter environment reduced decomposition when communities were inoculated into a hardwoodlitter environment. Our work demonstrates experimentally that despite expectations of fast growth rates, physiological
\end{abstract}

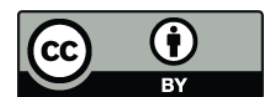

Correspondence to: A. D. Keiser (ashley.keiser@yale.edu) flexibility and rapid evolution, initial functional differences between microbial communities are maintained across time. These findings question whether microbial dynamics can be omitted from models of ecosystem processes if we are to predict reliably global change effects on biogeochemical cycles.

\section{Introduction}

Soil microbial communities play a pivotal role in ecosystems as drivers of biogeochemical processes, including carbon and nitrogen cycling (Allison and Martiny, 2008; Lauber et al., 2009; Bell et al., 2005; Fierer et al., 2007; Manzoni and Porporato, 2009; McGuire and Treseder, 2010; Wallenstein et al., 2010). How the activities of these communities will respond to environmental change, and hence influence carbon storage and nutrient availability, is an important research question for predicting future ecosystem function (Wallenstein et al., 2010). Given high species richness, fast growth rates, physiological flexibility and rapid evolution, soil microbial communities are traditionally assumed to be functionally similar with regard to broad-physiological processes such as the decomposition of organic carbon (Allison and Martiny, 2008; Schimel, 1995; Green et al., 2008; McGuire and Treseder, 2010). This assumption of similarity underlies the majority of terrestrial ecosystem models and is broadly defined as the ability of different microbial communities to carry out a functional process at a similar rate regardless of differences in composition (Allison and Martiny, 2008; Reed and Martiny, 2007).

Despite the expectation of functional similarity, microbial communities display biogeographic patterns generated not only by the contemporary environment (i.e. habitat) but

Published by Copernicus Publications on behalf of the European Geosciences Union. 
also historical factors, such as limited dispersal (Martiny et al., 2006; Ramette and Tiedje, 2007). Biogeographic heterogeneity provides conditions suitable for individuals and communities to adapt to their environment (Holt and Gomulkiewicz, 1997; Gholz et al., 2000; Strickland et al., $2009 \mathrm{~b}$ ). This indicates that the history of any one habitat might shape microbial community function under a new resource environment. To test for such historical effects one can compare ecosystem process rates in a common environment, inoculated with microbial communities sourced from different environments (Ayres et al., 2009; Langenheder and Prosser, 2008; Reed and Martiny, 2007; Strickland et al., 2009a). Using this approach, Strickland et al. (2009a) demonstrated that resource history generated functionally dissimilar communities, with history explaining between 22 and $86 \%$ of variance in the ecosystem process measured. What has not been resolved is whether these historical effects diminish as microbial communities respond to contemporary resource conditions. In other words, it is not apparent whether the communities become functionally more similar across time if exposed to a common environment. Such convergence in function might be expected if communities acclimate or adapt given physiological flexibility and natural selection, respectively. If initially distinct communities do become more functionally similar across time in a common environment then this might minimize the need to include microbial dynamics in predictive ecosystem models (see Allison and Martiny, 2008).

We used experimental microcosms, in a common garden design, to test whether initially distinct microbial communities exposed to common environments became more functionally similar (i.e. converge) across time $\left(\mathrm{H} 1_{\mathrm{a}}\right)$ or whether they remained functionally dissimilar $\left(\mathrm{H}_{\mathrm{b}}\right)$. Microbial inocula were collected from three, paired hardwood-grassland locations in the southeastern United States and introduced to common litter environments. After 100 days, the communities that developed were used to inoculate fresh litter environments and decomposition followed for another 100 days. We repeated this re-inoculation for a third, 100-day period (Appendix A). In addition to assessing function by measuring litter decomposition (as carbon mineralization rates), we also measured microbial community composition using genomic techniques at the end of the first and third 100-day period. Lastly, reciprocal inoculations were introduced in the third 100-day period. We placed microbial communities exposed to each of the common environments (either grass or hardwood litter) across the first two 100-day periods into the alternate litter environment for the third 100-day period (Appendix A). For example, communities experiencing the grass environment for two 100-day periods were inoculated into the hardwood environment, and vice-versa. This permitted us to test whether a change in function with exposure to one environment had consequences for function in an alternate environment. Specifically, we hypothesized that function is impaired when communities are moved to a less favorable (i.e. more chemically recalcitrant) resource environment, and maintained when communities are moved to more favorable resource environments $\left(\mathrm{H} 2_{\mathrm{a}}\right)$. The hardwood litter being the poor resource environment and the grass litter the rich. That is, "trade-offs" in function are asymmetric, which would be expected under the "functional breadth" hypothesis proposed by van der Heijden et al. (2008). This hypothesis states that microbial communities from poor resource environments maintain function across different environments because they're adapted to use a broad range of organic compounds, whereas communities from rich resource environments specialize on a narrower range of compounds and so have reduced function in poorer environments. Alternatively, function is simply a relative product of the contemporary environment $\left(\mathrm{H} 2_{\mathrm{b}}\right)$, which is consistent with the expectation that litter quality (e.g. initial C:N), for example, determines decomposition rates independent of the microbial community. Such assumptions are implicit in most predictive ecosystem models (see Allison and Martiny, 2008).

\section{Methods}

\subsection{Soil inocula and litter environments}

Soil microbial community inocula were collected from paired hardwood forest and grassland habitats at three locations: Coweeta Hydrologic Laboratory, North Carolina $\left(35^{\circ} 00^{\prime} \mathrm{N}, 83^{\circ} 30^{\prime} \mathrm{W}\right)$, Whitehall Forest, Georgia $\left(33^{\circ} 88^{\prime} \mathrm{N}\right.$, $83^{\circ} 36^{\prime} \mathrm{W}$ ), and Calhoun Experimental Forest, South Carolina $\left(34^{\circ} 63^{\prime} \mathrm{N}, 81^{\circ} 73^{\prime} \mathrm{W}\right)$. The locations span a regional physiographic gradient, ranging from mountains to mid- and low-piedmont, respectively. Soils at each location are Ultisols and have an acid $\mathrm{pH}$ (ranging from 4.35 in water at the Coweeta hardwood site to 5.75 at the Whitehall grassland site). The pairings and locations were chosen given the expectation that they would initially demonstrate differences in function in a common environment resulting from differences in historical environment (grass or forest) and geographic distance (locations are 145-225 km apart). Soils were collected from the surface $7.5 \mathrm{~cm}$ of the A horizon at each site from three, $25 \times 25 \mathrm{~cm}$ quadrats along a $10 \mathrm{~m}$ transect. Prior to collection, the litter layer was brushed aside. A pronounced Oe or Oa horizon does not develop at the sites, and thus the litter is in direct contact with the surface mineral horizon. Soils were passed through a $2 \mathrm{~mm}$ sieve and homogenized prior to microcosm set-up (below). Hereon we refer to them as: Coweeta grassland $=\mathrm{A}$, Coweeta hardwood $=\mathrm{B}$, Calhoun grassland $=\mathrm{C}$, Calhoun hardwood $=\mathrm{D}$, Whitehall grassland $=\mathrm{E}$, and Whitehall hardwood $=\mathrm{F}$.

Litters for the common environments were collected at Coweeta Hydrologic Laboratory as either standing-dead material (grass) or recent litterfall (hardwood). Schizachyrium scoparium (Michx.) Nash (little bluestem) served as the grass litter and Rhododendron maximum L. (rhododendron) 
as the hardwood. The grass litter was chemically less recalcitrant, with $44.9 \% \mathrm{C}, 0.51 \% \mathrm{~N}$ and $6.63 \%$ lignin, compared to for the hardwood $48.9 \% \mathrm{C}, 0.55 \% \mathrm{~N}$ and $12.54 \%$ lignin. Litter was air-dried and homogenized by passing through a Wiley mill ( $2 \mathrm{~mm}$ mesh). It was sterilized by autoclaving twice in succession at $120^{\circ} \mathrm{C}$ for $20 \mathrm{~min}$, and then again $24 \mathrm{~h}$ later, before drying to $65^{\circ} \mathrm{C}$ (Strickland et al., 2009a, b).

\subsection{Experimental design}

We used a $6 \times 2$ (soil inoculum $\times$ litter environment), fullfactorial design. Litter microcosms were constructed and maintained following Strickland et al. (2009a, b). Briefly, microcosms were $50 \mathrm{ml}$ plastic, centrifuge tubes containing $1 \mathrm{~g}$ litter and $0.5 \mathrm{~g}$ soil inoculum, homogeneously mixed. The soil inoculum represented approximately $20 \%$ of the overall volume, but the microcosm was a sufficient litter:soil mass ratio to sustain consistent microbial respiration through 100 days (see Strickland et al., 2009a). Six replicates were established for each litter (2) by inoculum (6) combination, giving 72 units per 100 day run. Water-holding capacities of the litter-soil mixes were adjusted by weight and maintained at $65 \%$ (Langenheder and Prosser, 2008), which is within the favorable range for microbial activity. The litter microcosms were kept at $20^{\circ} \mathrm{C}$ under $100 \%$ humidity (to prevent drying), and carbon mineralization was measured periodically over each 100-day run (see below). For the second 100-day run, microcosms were established with $1 \mathrm{~g}$ fresh litter and $0.15 \mathrm{~g}$ of the previous round's litter-soil mixture as the inoculum. This was repeated for a third, 100-day run (Appendix A). This design of inoculation of fresh litters across successive 100-day runs was designed to test whether functioning of microbial communities converges (i.e. becomes more similar) if they are exposed to a common resource environment. To explore whether recent history of one litter type led to loss of function on an alternate litter type, in the third 100-day run we also crossed inocula into the alternate environment resulting in 72 additional units. Specifically, if a community experienced grass litter in the first two rounds, it was then inoculated in the third round into a hardwood litter environment, and vice-versa (Appendix A).

\subsection{Carbon mineralization rates}

Carbon mineralization rates were measured twelve times across each 100-day run (days 2, 5, 8, 12, 17, 23, 30, 37, 45, 54, 75 and 100), following Strickland et al. (2009a, b). Briefly, for each measurement, centrifuge tubes were fitted with gas-tight lids modified with septa for gas analysis. They were flushed with $\mathrm{CO}_{2}$-free air and incubated for $24 \mathrm{~h}$. Headspace $\mathrm{CO}_{2}$ concentrations were measured using infra-red gas analysis (Li-COR model LI-7000, Lincoln, NE, USA). In each round, tubes with inocula only were established to determine inocula-derived $\mathrm{CO}_{2}$ efflux. These values were subtracted from the litter microcosm fluxes to estimate litter mineralization rates. Cumulative carbon mineralized for each replicate was determined by integrating rate values across each 100-day run.

\subsection{Microbial community composition}

We used a barcoded pyrosequencing procedure targeting the small-subunit rRNA gene in order to determine the structure of the bacterial and fungal communities at the end of the $100 \mathrm{~d}$ incubations for both rounds 1 and 3. As we would not necessarily expect the bacterial and fungal communities to respond in a similar manner to the litters, these two decomposer taxa were analyzed independently. We conducted the molecular analyses to test whether the composition of the communities in the microcosms converged between rounds 1 and 3 on their respective litters. In other words, we were testing whether communities became more compositionally similar on a given litter type regardless of the microbial inoculum. To keep sample numbers manageable, we only examined community differences for four, randomly-selected, inoculum-types per litter. This gave eight samples per round, with replicate microcosms of a given inoculum pooled together to produce a single composited sample, following Strickland et al. (2009a). The inocula selected for analysis in round 1 were also selected for round 3 to allow for comparison across time. DNA extractions, PCR amplifications, amplicon pooling, and sequence analyses were conducted as described previously (Rousk et al., 2010; Lauber et al., 2009). Sequencing was done at Engencore at the University of South Carolina on a Roche 454 GS-FLX automated sequencer. Only those samples which yielded $>1000$ quality bacterial and $>1000$ quality fungal sequences were included in the subsequent analyses. On average, the pyrosequencing yielded 2430 bacterial and 1550 fungal sequences per sample, and, for both groups, the reads were sufficiently long to obtain sequence data for the full length of the amplicons.

\subsection{Statistical analysis}

ANOVA was used to test between $\mathrm{H} 1_{\mathrm{a}}$ and $\mathrm{H} 1_{\mathrm{b}}$ (i.e. loss vs. maintenance of functional dissimilarity), by testing for effects on cumulative carbon mineralization of the litter environment (hardwood or grass), inoculum (A through F), and sampling round (one through three). All factors were permitted to interact and treated as discrete. We also generated cluster diagrams in R (Team, 2009) - based on Euclidean distance and Ward's method - to more easily visualize whether function converged across time. Specifically, this approach permitted us to examine with more certainty whether significant interactions between sampling round and litter environment and/or inoculum were associated with functional convergence (see Results).

To test between $\mathrm{H} 2_{\mathrm{a}}$ and $\mathrm{H} 2_{\mathrm{b}}$ (i.e. functional breadth vs. contemporary environment), we constructed a linear mixed effects model with the contemporary environment (grass or 
hardwood in round 3) and experimental resource history (grass or hardwood in rounds 1 and 2) as fixed effects. Inoculum (A through F) was not a factor of interest in this analysis but was included as a random effect to account for the spatial association between inocula from the same site (e.g. A and B) but with a different contemporary litter environment and/or experimental resource history. For statistical significance, we used an alpha of $<0.05$. Data were $\log _{e^{-}}$ transformed when necessary to conform to assumptions of homoscedasticity. ANOVAs and mixed-effect models were performed in the statistical freeware R (Team, 2009).

Sequence data were processed using the QIIME software package (Caporaso et al., 2010) using techniques employed previously with similar datasets (Rousk et al., 2010; Fierer et al., 2008; Lauber et al., 2009). Briefly, sequences were assigned to phylotypes at the $97 \%$ sequence similarity level and the phylotypes were classified by comparing representative sequences to those in curated databases. For both the bacterial and fungal data, matrices of proportional phylotype abundances per sample were square-root transformed with the pair-wise distance between each sample calculated using a Euclidean distance metric as implemented in PRIMERv6 (PRIMER-E Ltd, Ivybridge, UK). The resulting distance matrices were visualized using principal coordinates plots with the statistical significance of the community differences between litter types and rounds determined using ANOSIM (PRIMER-E Ltd, Ivybridge, UK).

\section{Results}

To test our competing hypotheses $1_{\mathrm{a}}$ and $1_{\mathrm{b}}$ (i.e. loss vs. maintenance of functional dissimilarity), we assessed whether initial functional differences (i.e. cumulative litter mineralization across 100 days in round 1) between inocula changed across successive rounds in a common environment. That there were initial functional differences between at least some of the inocula in round 1, for each litter environment, was confirmed by a significant inoculum effect (grass, $F_{5,30}=29.65, P<0.001$; hardwood, $F_{5,30}=27.175$, $P<0.001$, with inocula B and D differing to the greatest extent (Fig. 1). Also apparent were marked increases in function (i.e. cumulative mineralization) for all inocula in each successive sampling round (Fig. 1). Significant interactions between inoculum and round, for both environments (grass, $F_{10,90}=28.2, P<0.001$; hardwood, $F_{10,90}=11.37$, $P<0.001$ ), indicated that as function increased, the relative differences among inocula over the rounds also changed. For example, inoculum $\mathrm{C}$ moved from the lowest cumulative mineralization on grass in round 1 to the highest in round 3 (Fig. 1). Yet, shifts in relative function among inocula were not associated with increasing similarity in function across rounds $\left(\right.$ Hyp. $\left.1_{\mathrm{a}}\right)$; rather, functional differences were maintained overall (Hyp. $1_{\mathrm{b}}$ ). To more clearly observe these patterns, we constructed cluster diagrams for the rounds 1 and 3

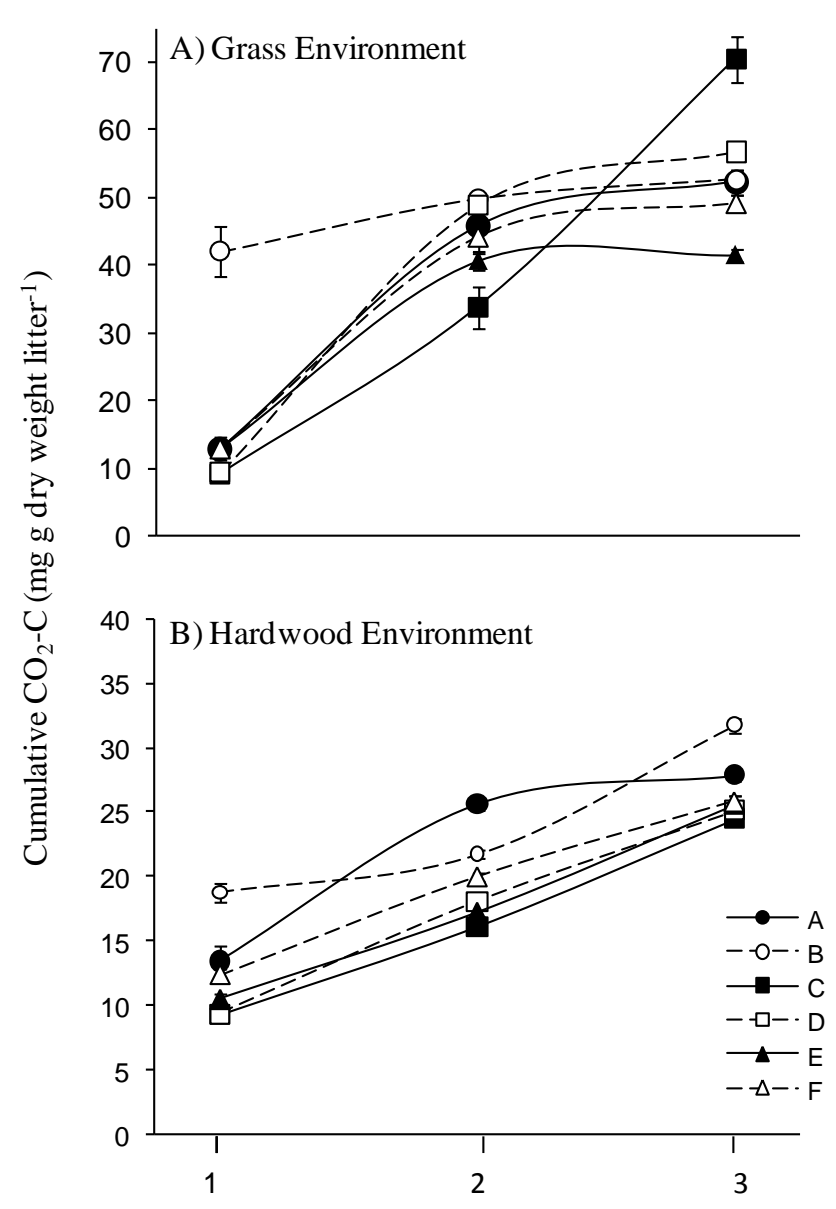

Sampling Round

Fig. 1. Cumulative litter decomposition across each 100-day sampling round for six different microbial community inocula in grass (A) and hardwood (B) environments. Closed symbols and solid lines represent inocula from grassland sites and open symbols and dashed lines from hardwood sites. Values are means $\pm 1 \mathrm{SE}$ $(n=6)$. For clarity, pair-wise comparisons are not shown. However, in each round at least three inocula are significantly different $(P \leq 0.05)$.

functional data (Fig. 2). They confirmed that the relative differences between inocula did change across sampling rounds, but overall dissimilarity was maintained (Fig. 2). For example, in the grass litter environment, inoculum B from round 1 clustered with the round 3 inocula; yet in round 3, inoculum B was functionally indistinguishable from inoculum A (Fig. 2a). Additionally, in both environments the function of inocula separated into two clusters in round one, but formed a single cluster by round three (Fig. 2). To further support our inference from the ANOVA and cluster diagram analyses that functional dissimilarity was maintained, we first compared the coefficients of variation (CV) among inocula for each litter type between rounds 1 and 3. Coefficients declined from rounds 1 to 3 where values were 0.757 and 0.294 

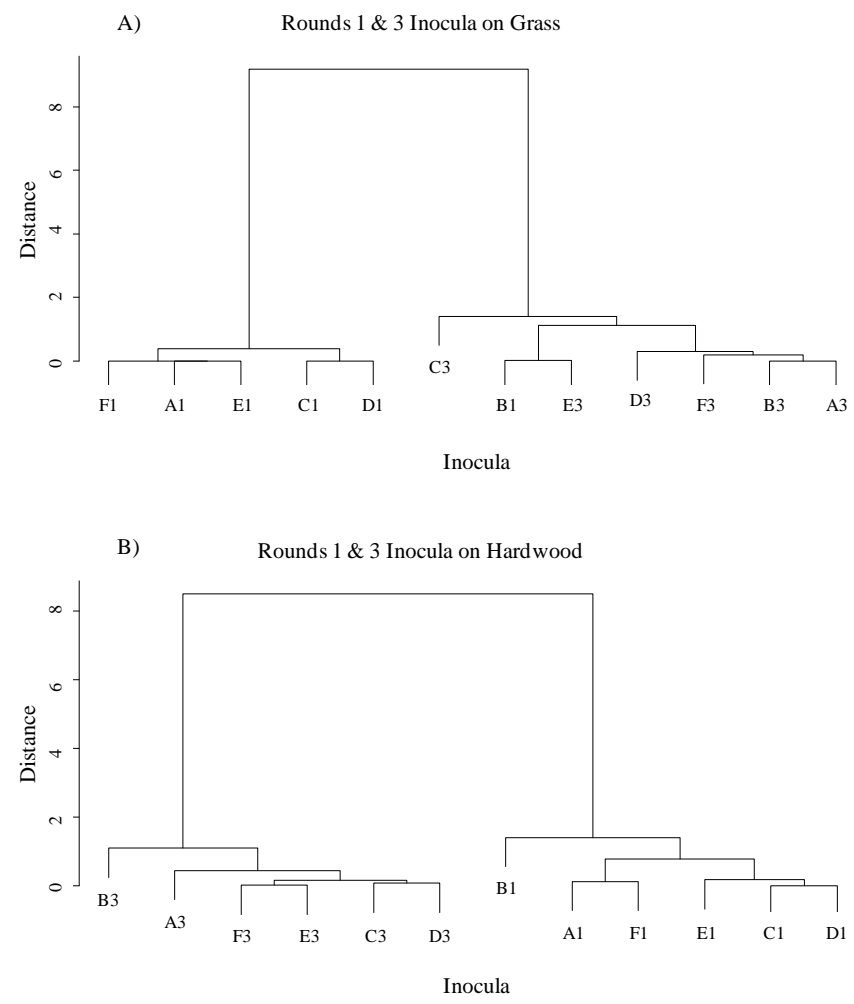

Fig. 2. Cluster diagrams, using Euclidean distance and Ward's method, for cumulative litter decomposition rates for inocula with a history of grass (A) or hardwood litter environments (B) in rounds 1 and 3 . For both the grass and hardwood litter environments, functioning across inocula is approximately equal within rounds, indicating that functional dissimilarity is maintained across time.

after 100 days and 0.178 and 0.101 after 300 days on grass and hardwood, respectively. However, a paired t-test of the variances between rounds 1 and 3 by litter type, ranked from smallest to largest variance, showed this decline was not significant: grass, $t_{5}=0.846, P=0.436$; hardwood, $t_{5}=1.716$, $P=0.147$. Overall, our data support hypothesis $1_{\mathrm{b}}$ for functional dissimilarity.

The maintenance of functional dissimilarity across rounds contrasted with the phylogenetic composition of the bacterial communities, where the communities clustered by litter type in round 3 but not in round 1 (Fig. 3a). This suggested that there was convergence of community composition over time in the same litter environment. A similar, though less dramatic, convergence was also observed in the fungal communities, with the composition clustering by litter type in round 3 (Fig. 3b).

The clustering of bacterial and fungal communities across time reflected shifts in the dominant taxa. At the end of round 1 , there was not a clear distinction between dominant taxa in the grass or hardwood environments (Tables 1,2), as visualized in the PCA plots of Fig. 3. For example, Alphaproteobacteria composed $29.43 \% \pm 8.64$ and $21.83 \% \pm 6.06$ of
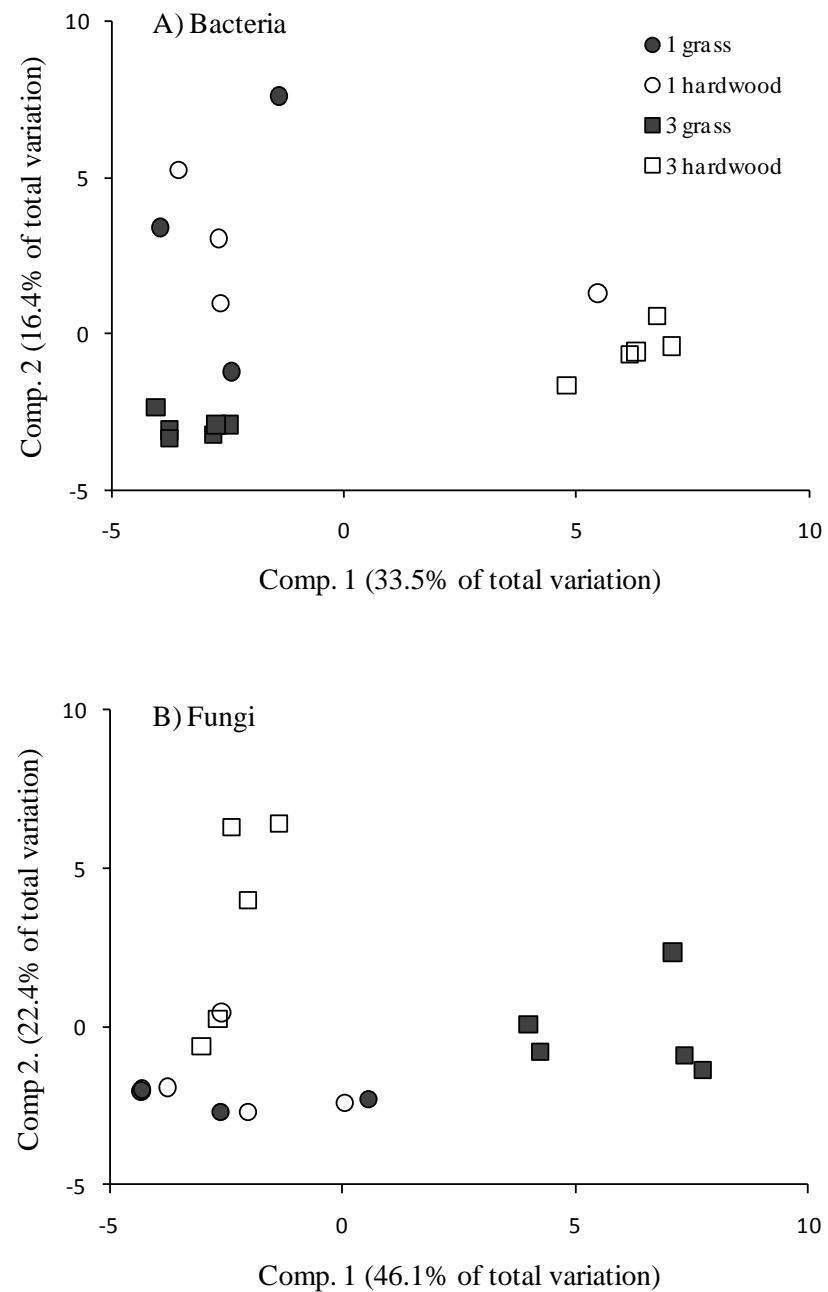

Fig. 3. Principle components plots of bacterial (A) and fungal (B) communities, using Euclidean distance (calculated from phylotype abundances), for inocula in round 1 (circles) or round 3 (squares). The phylogenetic composition of these inocula cluster by litter environment (grass or hardwood) in round 3 only, following exposure to these litter environments in previous rounds (1 and 2).

the total distribution on hardwood and grass, respectively (Table 1). The phylogenetic clustering by litter type in round 3 (Fig. 3) was concomitant with shifts in the dominant taxa. Alphaproteobacteria were more abundant in the hardwood environment $(59.26 \% \pm 8.64$ vs. $25.79 \% \pm 3.94$ on grass), while Actinobacteria, Bacteriodetes, and Gammaproteobacteria were more abundant in the grass environment (Table 1). By round 3, within the fungal sequences, those inocula in the grass environment had more Ascomycetes, and those in the hardwood environment had more Basidiomycetes $(4.6 \%$ in grass vs. $28 \%$ in hardwood). Within the Ascomycetes, the inocula on grass were dominated by Sordariomycetes while those on hardwood were dominated by Trichomaceae (Table 2). 
Table 1. Percent distribution of bacterial taxa averaged across inocula within a litter environment and sampling round. Each number represents the percent occurrence of a specific phylum or subphylum within the total number of bacterial sequences.

\begin{tabular}{|c|c|c|c|c|}
\hline \multirow[b]{3}{*}{ Community } & \multicolumn{4}{|c|}{ Grass Environment } \\
\hline & \multicolumn{2}{|c|}{ Round 1} & \multicolumn{2}{|c|}{ Round 3} \\
\hline & Average & Std. Error & Average & Std. Error \\
\hline Acidobacteria & 8.18 & 3.42 & 7.51 & 1.80 \\
\hline Actinobacteria & 17.85 & 2.66 & 13.07 & 4.88 \\
\hline Bacteroidetes & 3.66 & 2.61 & 19.28 & 6.81 \\
\hline Firmicutes & 6.82 & 5.62 & 0.10 & 0.04 \\
\hline Planctomycetes & 0.45 & 0.15 & 0.70 & 0.32 \\
\hline Alphaproteobacteria & 21.83 & 6.06 & 25.79 & 3.94 \\
\hline Betaproteobacteria & 18.99 & 3.92 & 11.01 & 2.03 \\
\hline Deltaproteobacteria & 0.21 & 0.11 & 0.09 & 0.04 \\
\hline Gammaproteobacteria & 4.43 & 1.64 & 19.26 & 7.18 \\
\hline Verrucomicrobia & 0.96 & 0.30 & 0.10 & 0.05 \\
\hline \multirow[t]{3}{*}{ Other } & 16.62 & 7.15 & 3.09 & 0.34 \\
\hline & \multicolumn{4}{|c|}{ Hardwood Environment } \\
\hline & \multicolumn{2}{|c|}{ Round 1} & \multicolumn{2}{|c|}{ Round 3} \\
\hline Community & Average & Std. Error & Average & Std. Error \\
\hline Acidobacteria & 7.66 & 3.23 & 15.40 & 3.65 \\
\hline Actinobacteria & 24.57 & 7.36 & 4.23 & 3.12 \\
\hline Bacteroidetes & 0.95 & 0.46 & 3.05 & 2.97 \\
\hline Firmicutes & 1.98 & 1.18 & 0.08 & 0.04 \\
\hline Planctomycetes & 1.46 & 0.94 & 0.08 & 0.08 \\
\hline Alphaproteobacteria & 29.43 & 8.64 & 59.26 & 8.64 \\
\hline Betaproteobacteria & 13.64 & 5.73 & 7.42 & 2.90 \\
\hline Deltaproteobacteria & 0.36 & 0.18 & 0.10 & 0.10 \\
\hline Gammaproteobacteria & 3.43 & 1.34 & 3.43 & 2.96 \\
\hline Verrucomicrobia & 1.02 & 0.71 & 0.01 & 0.01 \\
\hline Other & 15.49 & 3.82 & 6.94 & 1.60 \\
\hline
\end{tabular}

To test our second pair of hypotheses (functional breadth vs. contemporary environment), we crossed inocula that had experienced one litter environment for rounds 1 and 2 into the alternate environment during round 3 . We assessed these hypotheses using two levels of inquiry. For the first, we asked the question using all six inocula and found marked effects of rounds 1-2 history on function in round 3. A significant interaction $\left(F_{1,120}=1075, P<0.001\right)$ between historical and contemporary environment indicated the effects were environment dependent. Specifically, inocula with an experimental history of grass litter in rounds 1 and 2 had cumulative mineralization rates $\sim 4$ fold higher $\left(F_{1,70}=700\right.$, $P<0.001)$ in the round 3 grass than hardwood environment (Fig. 4a). In contrast, inocula with a history of hardwood litter in rounds 1 and 2 had more similar rates $\left(F_{1,70}=14.24\right.$, $P<0.001)$ in both grass and hardwood litter environments in round 3 . These results support the functional breadth hypothesis. For the second level of inquiry we used only inocula A and $\mathrm{B}$ given that these inocula were sourced from the same location (Coweeta) as the litters used to construct the microcosms, meaning the inocula had a pre-experimental history of the grass (inoculum A) and hardwood (inoculum B) litters.
Table 2. Percent distribution of fungal taxa averaged across inocula within a litter environment and sampling round. Each number represents the percent occurrence of a specific phylum or sub-phylum within the total number of fungal sequences.

\begin{tabular}{|c|c|c|c|c|}
\hline \multirow[b]{3}{*}{ Community } & \multicolumn{4}{|c|}{ Grass Environment } \\
\hline & \multicolumn{2}{|c|}{ Round 1} & \multicolumn{2}{|c|}{ Round 3} \\
\hline & Average & Std. Error & Average & Std. Error \\
\hline Ascomycota & 96.85 & 1.85 & 92.18 & 3.75 \\
\hline Dothideomycetes & 2.78 & 0.68 & 10.79 & 4.24 \\
\hline Herpotrichiellaceae & 0.20 & 0.03 & 0.49 & 0.27 \\
\hline Lecanoromycetes_2 & 0.00 & 0.00 & 0.1 & 0.03 \\
\hline Myxotrichum et rel. & 2.62 & 2.04 & 4.88 & 1.42 \\
\hline Onygenales & 0.02 & 0.02 & 0.01 & 0.01 \\
\hline Saccharomycotina & 0.14 & 0.14 & 0.08 & 0.03 \\
\hline Sordariomycetes & 21.89 & 11.67 & 67.4 & 9.03 \\
\hline Thelebolaceae & 0.02 & 0.02 & 0.04 & 0.02 \\
\hline Trichocomaceae & 68.85 & 16.22 & 7.29 & 2.45 \\
\hline Basidiomycota & 0.23 & 0.17 & 4.64 & 3.70 \\
\hline Agaricostilbum et rel. & 0.00 & 0.00 & 2.1 & 1.93 \\
\hline Graphiola et rel. & 0.02 & 0.02 & 0.02 & 0.01 \\
\hline Hymenomycetidae & 0.00 & 0.00 & 0 & 0.00 \\
\hline Tremellales et rel. & 0.19 & 0.13 & 2.47 & 1.78 \\
\hline Zygomycota_1 et rel. & 2.43 & 1.47 & 0.83 & 0.52 \\
\hline Mucorales & 2.43 & 1.47 & 0.83 & 0.52 \\
\hline \multirow[t]{3}{*}{ Other } & 0.49 & 0.22 & 2.35 & 2.14 \\
\hline & \multicolumn{4}{|c|}{ Hardwood Environment } \\
\hline & \multicolumn{2}{|c|}{ Round 1} & \multicolumn{2}{|c|}{ Round 3} \\
\hline Community & Average & Std. Error & Average & Std. Error \\
\hline Ascomycota & 98.64 & 0.48 & 70.77 & 10.56 \\
\hline Dothideomycetes & 2.31 & 0.58 & 1.06 & 0.18 \\
\hline Herpotrichiellaceae & 0.09 & 0.04 & 0.28 & 0.24 \\
\hline Lecanoromycetes_2 & 0.00 & 0.00 & 0.01 & 0.01 \\
\hline Myxotrichum et rel. & 1.32 & 0.71 & 2.95 & 1.24 \\
\hline Onygenales & 0.02 & 0.02 & 0.01 & 0.01 \\
\hline Saccharomycotina & 0.06 & 0.05 & 0.1 & 0.04 \\
\hline Sordariomycetes & 21.18 & 8.15 & 13.25 & 1.33 \\
\hline Thelebolaceae & 0.04 & 0.01 & 0 & 0 \\
\hline Trichocomaceae & 73.44 & 9.81 & 52.8 & 9.94 \\
\hline Basidiomycota & 0.66 & 0.43 & 27.93 & 10.72 \\
\hline Agaricostilbum et rel. & 0.00 & 0.00 & 0 & 0 \\
\hline Graphiola et rel. & 0.00 & 0.00 & 0.01 & 0.01 \\
\hline Hymenomycetidae & 0.00 & 0.00 & 0.18 & 0.18 \\
\hline Tremellales et rel. & 0.64 & 0.44 & 27.63 & 10.87 \\
\hline Zygomycota_1 et rel. & 0.51 & 0.27 & 0.01 & 0.01 \\
\hline Mucorales & 0.51 & 0.27 & 0.01 & 0.01 \\
\hline Other & 0.19 & 0.08 & 1.28 & 0.44 \\
\hline
\end{tabular}

As such, we could ask whether function in round 1 differed from that in round 3 if the inocula experienced an alternate environment in rounds 1 and 2 . We found that the grassland inoculum (A), after experiencing the hardwood environment for rounds 1 and 2, increased its function (i.e. litter mineralization) on grass litter $\left(t_{5}=-4.578, P<0.01\right)$ in round 


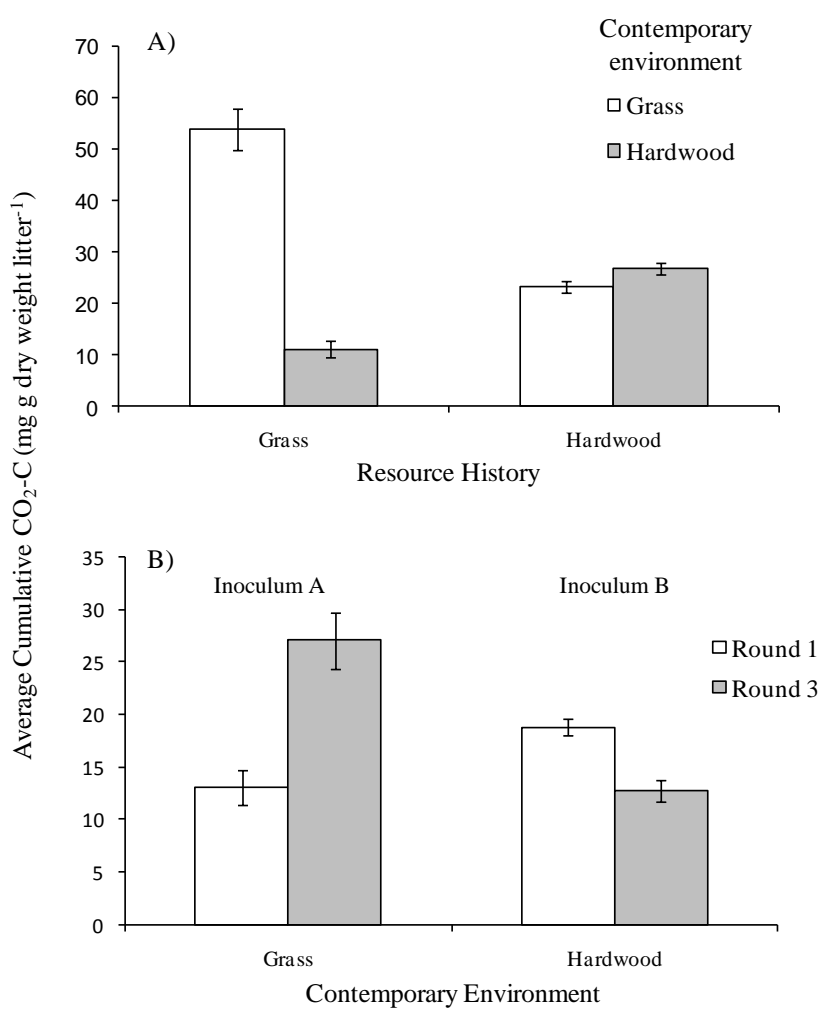

Fig. 4. Cumulative litter decomposition for inocula exposed to grass or hardwood litter environments and then placed in the same environment or switched into the alternate environment. In (A), exposure to the grass litter environment in rounds 1 and 2 (resource history) leads to reduced decomposition in the hardwood compared to the grass litter environment in round 3 (contemporary environment), but no such loss of function is associated with history of exposure to the hardwood environment when inocula are placed into the two environments in round 3. Values are means $\pm 1 \mathrm{SE}(n=36)$. In (B), the function of a single inoculum, (A or B) on a single litter type (grass or hardwood, respectfully), is compared between rounds 1 (white bars) and 3 (grey bars). The round 1 inocula are sourced from the same field location used to construct the microcosms (preexperimental). After two rounds in hardwood litter, inoculum A increases function in a grass environment as compared to round 1 (a pre-experimental history of grass). In contrast, after two rounds in grass litter, inoculum B decreases function in a hardwood environment as compared to round 1 (a pre-experimental history of hardwood). Values are means $\pm 1 \mathrm{SE}(n=6)$.

3 as compared to round 1 (Fig. $4 \mathrm{~b}$ ). In contrast, the hardwood inoculum (B), after experiencing the grass environment for rounds 1 and 2 , had reduced function on hardwood litter $\left(t_{5}=3.798, P<0.05\right)$ in round 3 as compared to round 1 (Fig. 4b). Again, these findings support the functional breath hypothesis.

\section{Discussion}

We established an experimental design to test two sets of competing hypotheses. In the first set, we tested whether distinct microbial communities exposed to common environments became more functionally similar across time $\left(\mathrm{H} 1_{\mathrm{a}}\right)$ or whether they remained dissimilar $\left(\mathrm{H} 1_{b}\right)$. In contrast to the assumption of functional similarity that underlies the majority of terrestrial ecosystem models (Allison and Martiny, 2008; Reed and Martiny, 2007), which posits that only the contemporary environment affects process rates, litter mineralization remained dissimilar across inocula that had the same experimental resource histories (Figs. 1 and 2). Nevertheless, litter mineralization rates increased with exposure to a common environment (Fig. 1). This increase in function across rounds 1 to 3 is commensurate with observations that exposure of the microbial community to a specific litter accelerates the litter's decomposition in the contemporary environment (Ayres et al., 2009; Strickland et al., 2009a, b; Wallenstein et al., 2010). Interestingly, the soil inoculum sourced from the hardwood environment (inoculum B) had the greatest initial litter mineralization (Fig. 1), suggesting "home-field advantage" (Gholz et al., 2000; Hunt et al., 1988). Our study design further demonstrates this "homefield advantage" phenomenon (Gholz et al., 2000; Hunt et al., 1988) for the first time through the generation of experimental resource histories. These gains in function are consistent with the expected properties of microbial communities - fast growth rates, physiological flexibility and rapid evolution that enable them to respond rapidly to new conditions (Allison and Martiny, 2008). However, it is an open question as to whether these same properties of microbial communities negate initial functional dissimilarity (Strickland et al., 2009b). Our findings suggest that despite marked gains in function (Fig. 1), dissimilarity is maintained. This indicates that ecosystem process rates in contemporary environments, even long after a disturbance, are likely dependent, in part, on historical factors. It is possible that microfauna could be contributing equally to the observed patterns; however, we do not believe their presence or absence caused observed differences between treatments (dissimilarity). Future work is required to determine the mechanisms maintaining dissimilarity, which may include contrasting genetic potentials and/or biotic interactions.

To understand how responses of microbial community composition to disturbance affect ecosystem processes, Allison and Martiny (2008) highlight the need for an improved understanding between microbial phylogeny and function. Although there are phylogenetic signals of physiological traits (e.g. Fierer et al., 2007), we found contrasting results. Despite observations of functional dissimilarity in rounds 1 and 3, phylogenetic composition of the communities was distinct in round 1 but converged (by litter environment) in round 3 (Fig. 3 and Tables 1 and 2). Given that our study used an experimental design that separates effects of microbial community composition on function from the contemporary environment (see Allison and Martiny, 2008; Reed and Martiny, 2007; Strickland et al., 2009b), it seems clear that functional dissimilarity arose from differences in microbial 
composition. Yet the disconnect between the functional and phylogenetic clustering suggests that the $>97 \%$ sequence similarity that we used to distinguish phylotypes was not an effective resolution for linking microbial phylogeny to function. To enable prediction of the functional consequences of changes in the phylogenetic composition of microbial communities requires further work to resolve the genetic scale at which functional traits are clustered. The bacterial data (Table 1) do indicate dominance by copiotrophic taxa, or $r$-strategists, which have fast growth rates and are generally found utilizing labile organic carbon pools (Fierer et al., 2007). Copiotrophs include Betaproteobacteria, and, oftentimes, Alphaprotebacteria while Actinobacteria are not consistently copiotrophic or oligotrophic ( $K$-strategist) (Fierer et al., 2007). These copiotrophic phyla would be expected in a more organic, nutrient rich, litter environment.

Our second set of competing hypotheses $\left(\mathrm{H} 2_{\mathrm{a}, \mathrm{b}}\right)$ concerned whether a change in function with exposure to one environment has consequences for function in an alternate environment. Strickland et al. (2009a) showed that the perception of litter quality by a microbial community appeared dependent on the litter resources to which it has been exposed. Specifically, their observations fit with the "functional breadth hypothesis" (van der Heijden et al., 2008), which posits that microbial communities from nutrient poor (as opposed to nutrient rich) environments likely have higher functional diversity because they are adapted to utilize a greater range of complex/ recalcitrant compounds. Our study design permitted us to test this hypothesis using known experimental histories and contemporary environments under tightlycontrolled conditions. We found that exposure to the more chemically-recalcitrant resource environment (hardwood) in rounds 1 and 2 meant that litter decomposition rates were similar in round 3 whether the communities were inoculated into grass or hardwood environments (Fig. 4a). In contrast, exposure to the less chemically-recalcitrant resource environment (grass) was associated with loss of function (i.e. lower mineralization rates) on hardwood litter in round 3 (Fig. 4a). So, the perception of "litter quality" was dependent on the experimental resource history, providing support for the functional breadth hypothesis. Also consistent with functional breadth, the two inocula (A and B) collected from the same location (i.e. Coweeta) as the litters displayed changes in function across the experiment that were dependent on the experimental litter to which they were exposed. Specifically, the grassland inoculum (A) had higher function on its "home" grass litter in round 3 (than 1) after exposure to hardwood in rounds 1 and 2 (Fig. 4b). The hardwood inoculum (B) had lower function on its "home" hardwood litter in round 3 (than 1) after exposure to grass in rounds 1 and 2 (Fig. 4b). These data are consistent with the expectation that microbial communities respond rapidly to environmental change, and demonstrate this rapid response for function. It should be noted that autoclaving, the method chosen to sterilize the litter, may have differentially altered the two litter types. This may have caused, if anything, an underestimation of differences in mineralization rates. Sterilization also removed any epiphytic microbes which may have initially colonized the litter. There is no evidence that epiphytic microbes affect functional similarity or dissimilarity of soil microbial communities (Osono, 2007; Osono and Hirose, 2011); however, there is a need for further research exploring the interaction between epiphytic and soil microbial communities.

Collectively, our findings confirm that decomposition rates cannot be simply predicted from litter chemical characteristics, but rather the microbial community decomposing the litter needs to be taken into account (Strickland et al., 2009a). This might help explain why in some environments litters decompose at rates different to those predicted from climate and litter chemistry (Gholz et al., 2000; Hunt et al., 1988). Most notably, our findings show that despite rapid gains in function given exposure to a given litter environment, as well as changes in functional breadth, functional dissimilarity is maintained across microbial communities. Phylogenetic shifts in the composition of the microbial communities did not appear to explain observed functional dissimilarity. Indeed, microbial communities are highly complex entities, making identification of mechanisms underlying the effects of history on ecosystem processes difficult to unravel (Allison and Martiny, 2008; Bradford et al., 2008; Green et al., 2008). Differences might arise from physiological adjustments of individuals, capacity for colonization, evolutionary adaptation, epigenetics, and/or shifts in the abundance of different taxa (Goddard and Bradford, 2003; Bossdorf et al., 2008; Fukami et al., 2010). What is clear from our results is the potential for initial microbial functional dissimilarity to be maintained despite a recent history of the same environment. It is important to note that during the earlier stages of litter decomposition, we would expect to find many more taxa with a shared ability to degrade more labile compounds (Goldfarb et al., 2011), and thus, more likely to find a process which is buffered against environmental perturbations (Schimel, 1995; Allison and Martiny, 2008). Field data on carbon and nitrogen processes have revealed a role for microbial community composition in more specialized processes requiring fewer taxa, but not necessarily more general processes such as carbon mineralization (e.g. Balser and Firestone, 2005). Current theory and empirical data would then suggest that our test for functional similarity/ dissimilarity across the first 100 days of litter degradation would favor convergence. However, our data support the counter hypothesis of maintained dissimilarity. This finding emphasizes the need to consider microbial dynamics explicitly within ecosystem models (e.g. Allison et al., 2010). Our data further suggest that microbial community function is, as for plant and animal communities, structured at least in part by history. 


\section{Appendix A}

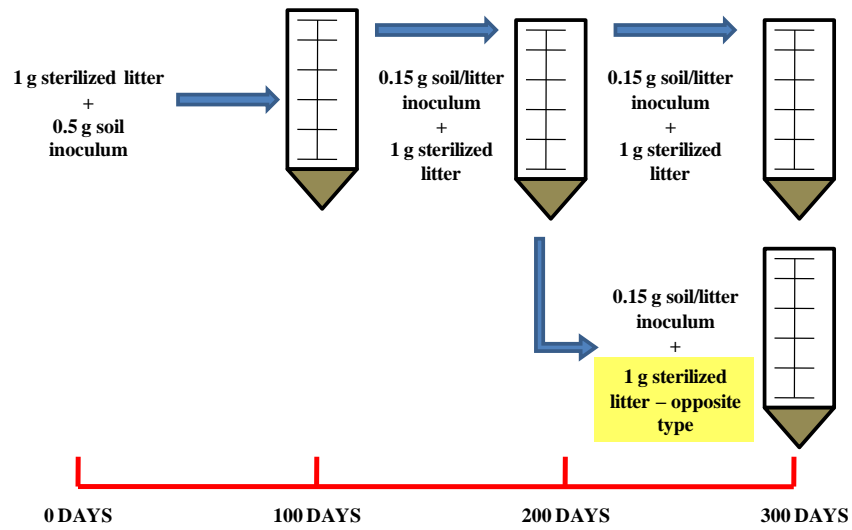

Fig. A1. Illustration of the experimental design.

Acknowledgements. This research was funded by the Andrew W. Mellon Foundation to MAB and NF, and the US National Science Foundation for the Coweeta LTER Program to MAB, and the Doctoral Dissertation Improvement Grant program to MAB and MSS. We would also like to thank Chris Lauber and Donna Berg-Lyons for their help with the molecular analyses.

Edited by: M. Bahn

\section{References}

Allison, S. D. and Martiny, J. B. H.: Resistance, resilience, and redundancy in microbial communities, P. Natl. Acad. Sci. USA, 105, 11512-11519, 2008.

Allison, S. D., Wallenstein, M. D., and Bradford, M. A.: Soilcarbon response to warming dependent on microbial physiology, Nat. Geosci., 3, 336-340, 2010.

Ayres, E., Steltzer, H., Berg, S., and Wall, D. H.: Soil biota accelerate decomposition in high-elevation forests by specializing in the breakdown of litter produced by the plant species above them, J. Ecol., 97, 901-912, 2009.

Balser, T. C. and Firestone, M. K.: Linking microbial community composition and soil processes in a California annual grassland and mixed-conifer forest, Biogeochemistry, 73, 395-415, 2005.

Bell, T., Newman, J. A., Silverman, B. W., Turner, S. L., and Lilley, A. K.: The contribution of species richness and composition to bacterial services, Nature, 436, 1157-1160, 2005.

Bossdorf, O., Richards, C. L., and Pigliucci, M.: Epigenetics for ecologists, Ecol. Lett., 11, 106-115, 2008.

Bradford, M. A., Davies, C. A., Frey, S. D., Maddox, T. R., Melillo, J. M., Mohan, J. E., Reynolds, J. F., Treseder, K. K., and Wallenstein, M. D.: Thermal adaptation of soil microbial respiration to elevated temperature, Ecol. Lett., 11, 1316-1327, 2008.

Caporaso, J. G., Kuczynski, J., Stombaugh, J., Bittinger, K., Bushman, F. D., Costello, E. K., Fierer, N., Gonzalez Pena, A., Goodrich, J. K., Gordon, J. I., Huttley, G. A., Kelley, S. T., Knights, D., Koenig, J. E., Ley, R. E., Lozupone, C. A., McDonald, D., Muegge, B. D., Pirrung, M., Reeder, J., Sevinsky, J. R., Turnbaugh, P. J., Walters, W. A., Widmann, J., Yatsunenko,
T., Zaneveld, J., and Knight, R.: QIIME allows analysis of highthroughput community sequencing data, Nat. Methods, 7, 335336, 2010.

Fierer, N., Bradford, M. A., and Jackson, R. B.: Toward an ecological classification of soil bacteria, Ecology, 88, 1354-1364, 2007.

Fierer, N., Hamady, M., Lauber, C. L., and Knight, R.: The influence of sex, handedness, and washing on the diversity of hand surface bacteria, P. Natl. Acad. Sci. USA, 105, 17994-17999, 2008.

Fukami, T., Dickie, I. A., Wilkie, J. P., Paulus, B. C., Park, D., Roberts, A., Buchanan, P. K., and Allen, R. B.: Assembly history dictates ecosystem functioning: evidence from wood decomposer communities, Ecol. Lett., 13, 675-684, 2010.

Gholz, H. L., Wedin, D. A., Smitherman, S. M., Harmon, M. E., and Parton, W. J.: Long-term dynamics of pine and hardwood litter in contrasting environments: toward a global model of decomposition, Glob. Change Biol., 6, 751-765, 2000.

Goddard, M. R. and Bradford, M. A.: The adaptive response of a natural microbial population to carbon- and nitrogen-limitation, Ecol. Lett., 6, 594-598, 2003.

Goldfarb, K. C., Karaoz, U., Hanson, C. A., Santee, C. A., Bradford, M. A., Treseder, K. K., Wallenstein, M. D., and Brodie, E. L.: Differential growth responses of soil bacterial taxa to carbon substrates of varying chemical recalcitrance, Front. Microbio., 2, 94, doi:10.3389/fmicb.2011.00094, 2011.

Green, J. L., Bohannan, B. J. M., and Whitaker, R. J.: Microbial biogeography: From taxonomy to traits, Science, 320, 10391043, 2008.

Holt, R. D. and Gomulkiewicz, R.: How does immigration influence local adaptation? A reexamination of a familiar paradigm, Am. Nat., 149, 563-572, 1997.

Hunt, H. W., Ingham, E. R., Coleman, D. C., Elliott, E. T., and Reid, C. P. P.: Nitrogen limitation of production and decomposition in prarie, mountain meadow, and pine forest, Ecology, 69, 10091016, 1988.

Langenheder, S. and Prosser, J. I.: Resource availability influences the diversity of a functional group of heterotrophic soil bacteria, Environ. Microbiol., 10, 2245-2256, 2008.

Lauber, C. L., Hamady, M., Knight, R., and Fierer, N.: Pyrosequencing-based assessment of soil $\mathrm{pH}$ as a predictor of soil bacterial community structure at the continental scale, Appl. Environ. Microb., 75, 5111-5120, 2009.

Manzoni, S. and Porporato, A.: Soil carbon and nitrogen mineralization: Theory and models across scales, Soil Biol. Biochem. 41, 1355-1379, 2009.

Martiny, J. B. H., Bohannan, B. J. M., Brown, J. H., Colwell, R. K., Fuhrman, J. A., Green, J. L., Horner-Devine, M. C., Kane, M., Krumins, J. A., Kuske, C. R., Morin, P. J., Naeem, S., Ovreas, L., Reysenbach, A. L., Smith, V. H., and Staley, J. T.: Microbial biogeography: putting microorganisms on the map, Nat. Rev. Microbiol., 4, 102-112, 2006.

McGuire, K. L. and Treseder, K. K.: Microbial communities and their relevance for ecosystem models: Decomposition as a case study, Soil Biol. Biochem., 42, 529-535, 2010.

Osono, T.: Ecology of ligninolytic fungi associated with leaf litter decomposition, Ecol. Res., 22, 955-974, 2007.

Osono, T. and Hirose, D.: Colonization and lignin decomposition of pine needle litter by Lophodermium pinastri, Forest Pathol. 
41, 156-162, 2011.

Ramette, A. and Tiedje, J. M.: Multiscale responses of microbial life to spatial distance and environmental heterogeneity in a patchy ecosystem, P. Natl. Acad. Sci. USA., 104, 2761-2766, 2007.

Reed, H. E. and Martiny, J. B. H.: Testing the functional significance of microbial composition in natural communities, FEMS Microbiol. Ecol., 62, 161-170, 2007.

Rousk, J., Baath, E., Brookes, P. C., Lauber, C. L., Lozupone, C., Caporaso, J. G., Knight, R., and Fierer, N.: Soil bacterial and fungal communities across a $\mathrm{pH}$ gradient in an arable soil, International Society for Microbial Ecology, 4, 1-12, 2010.

Schimel, J. P.: Ecosystem consequences of microbial diversity and community structure, in: Arctic and Alpine Biodiversity, Ecological Studies vol. 113, edited by: Chapin, F. S. and Korner, C., Springer-Verlag, New York, 239-254, 1995.
Strickland, M. S., Lauber, C., Fierer, N., and Bradford, M. A.: Testing the functional significance of microbial community composition, Ecology, 90, 441-451, 2009a.

Strickland, M. S., Osburn, E., Lauber, C., Fierer, N., and Bradford, M. A.: Litter quality is in the eye of the beholder: initial decomposition rates as a function of inoculum characteristics, Funct. Ecol., 23, 627-636, 2009b.

van der Heijden, M. G. A., Bardgett, R. D., and van Straalen, N. M.: The unseen majority: soil microbes as drivers of plant diversity and productivity in terrestrial ecosystems, Ecol. Lett., 11, 296310, 2008.

Wallenstein, M. D., Hess, A. M., Lewis, M. R., Steltzerae, H., and Ayres, E.: Decomposition of aspen leaf litter results in unique metabolomes when decomposed under different tree species, Soil Biol. Biochem., 42, 484-490, 2010. 